\title{
A new approach to geophysical real-time measurements on a deep-sea floor using decommissioned submarine cables
}

\author{
Junzo Kasahara ${ }^{1}$, Toshinori Sato ${ }^{1}$, Hiroyasu Momma ${ }^{2}$, and Yuichi Shirasaki ${ }^{3}$ \\ ${ }^{1}$ Earthquake Research Institute, University of Tokyo, 1-1-1 Yayoi-cho, Bunkyo-ku, Tokyo 113-0032, Japan \\ ${ }^{2}$ JAMSTEC (Japan Marine Science and Technology Center), 2-15 Natsushima, Yokosuka, Kanagawa 237-0061, Japan \\ ${ }^{3}$ KDD R \& D Laboratories, 2-1-15 Ohara, Kamifukuoka-shi, Saitama 356-0003, Japan
}

(Received April 8, 1998; Revised October 16, 1998; Accepted October 17, 1998)

\begin{abstract}
In order to better understand earthquake generation, tectonics at plate boundaries, and better image the Earth's deep structures, real-time geophysical measurements in the ocean are required. We therefore attempted to use decommissioned submarine cables, TPC-1 and TPC-2. An OBS was successfully linked to the TPC-1 on the landward slope of the Izu-Bonin Trench in 1997. The OBS detected co-seismic and gradual changes during a Mw 6.1 earthquake just below the station at $80 \mathrm{~km}$ depth on November 11, 1997. A pressure sensor co-registered a change equivalent to $50 \mathrm{~cm}$ sea-level change. This suggests a high possibility detecting silent earthquakes or earthquake precursors if they exist.

A multi-disciplinary geophysical station has been developed for deep-sea floor using TPC-2 since 1995. The station comprises eight instrument sets: broadband seismometers, geodetic measurements, hydrophone array, deepsea digital camera, CTD, etc.

These activities are examples that decommissioned submarine cables can be great global resources for real-time cost-effective geophysical measurements on a deep-sea floor.
\end{abstract}

\section{Introduction}

Recently, precise solutions of the Earth's structure have been obtained by body-wave travel-time tomography, especially by using ISC travel-time data (e.g., Grand et al., 1997; van der Hilst et al., 1997). The results show several important features such as the existence of high-velocity zone below the Eurasian Continent at the CMB and a high-velocity belt from Turkey to Vietnam at a depth of $1,200 \mathrm{~km}$. In contrast to the high-resolution images of the deep mantle structure, the resolution of the shallow mantle structure in the oceanic region is very poor, because there are very few available seismic data for the oceanic region. Although surface wave tomographic studies (e.g., Zhang and Tanimoto, 1993) could give structural models of the Earth in the ocean region for shallow mantle, spatial resolution is limited due to the nature of surface waves.

Destructive earthquakes have frequently occurred along plate convergent margins such as at the Japan Trench and the Nankai Trough. A real-time monitoring of earthquake wave-forms from the oceanic region may greatly contribute to minimizing the extent of damage by understanding the precise earthquake source mechanism. Real-time crustal deformation measurements at subduction zone may also provide significant keys to the existence of earthquake precursors, deformation process during large earthquakes, and existence of silent earthquakes, as shown by recent observations by the IZU OBS (Ocean Bottom Seismometer) described later. Geodetic measurements at trench slopes have not been car-

Copy right $(\mathrm{C}$ The Society of Geomagnetism and Earth, Planetary and Space Sciences (SGEPSS); The Seismological Society of Japan; The Volcanological Society of Japan; The Geodetic Society of Japan; The Japanese Society for Planetary Sciences. ried out because of technological difficulties.

The Izu-Bonin and the Mariana arcs (approximately $2,500 \mathrm{~km}$ long) are important areas for understanding plate subduction and back-arc spreading yet still not well understood. These arcs are characterized by the existence of active submarine volcanism at back-arc basins and serpentinite diapirs at the forearc slope. Myojin-syo along the volcanic front, which showed repeated emergence and subsidence, is one of the most active submarine volcanoes. The middle part of the Mariana Trough has a similar bathymetric profile as the Mid-Atlantic Ridge (Kong et al., 1992; Kasahara et $a l ., 1993$ ) and supports the idea of the occurrence of a slow spreading or rifting process in the middle Mariana Trough (Karig, 1971; Karig et al., 1978). High-temperature $\left(280^{\circ} \mathrm{C}\right)$ hydrothermal vents have also been found in the axial part of Mariana Trough at $18^{\circ} \mathrm{N}$ (Craig et al., 1987). Although the axial part of the southern the Mariana Trough shows smooth bathymetry, active hydrothermal vents have been found at the top of a seamount $30 \mathrm{~km}$ east of the axial zone (Gamo et al., 1994; Kasahara et al., 1994). Both areas are covered by pillow lava (Hawkins et al., 1990; Gamo et al., 1994; Kasahara et al., 1994). The existence of submarine volcanism and hydrothermal zones suggests the possibility of a young backarc rifting system in the southern to middle Mariana Trough.

The forearc basins of the Izu-Bonin has serpentinite diapirs (Ishii et al., 1992), which suggest uplifting of lighter materials due to hydration of mantle peridotite. At the seaward slopes of the Izu-Bonin and Mariana trenches, distinct normal faults structures reaching vertical displacements of up to several hundred meters can be observed (Kuramoto et al., 1991; Hydrographic Office Chart Nos. 6301, 6726). A large 
normal fault earthquake occurred at the Mariana Trench in 1990 (Yoshida et al., 1990) similar to the 1933 Great Sanriku earthquake.

The Philippine Sea plate subducts beneath the Nanseisyoto arc. Along the Nansei-syoto (Ryukyu) Trench, several large earthquakes occurred in the past. The Kikai-jima earthquake (M8.0) in 1911 is one example. A huge tsunami (the Great Meiwa Tsunami or Yaeyama Earthquake Tsunami, M7.4) attacked Ishigaki-jima at the western part of Nanseisyoto arc in 1771 . The height of the tsunami was up to $80 \mathrm{~m}$ (Matsumoto et al., 1997). Although the source mechanism of this huge tsunami is still under debate, the main cause of such large tsunamis and earthquakes seems to be the collisions of the Philippine Sea plate and the Nansei-syoto arc.

Therefore, it is important to increase geophysical observatories at the Izu-Bonin, Mariana, and Nansei-syoto arcs. The TPC-1 (Trans Pacific Cable-1) and the TPC-2 (Trans Pacific Cable-2) provide the key infrastructure for geophysical observations, because these cables run along the Izu-Bonin Trench, the north-to-middle Mariana Trough and the Nanseisyoto Trench, and across the entire Philippine Sea plate and the southern Mariana Trough.

\section{Technologies for Real-Time Observations on a Deep-Sea Floor}

For deep-sea real-time measurements, two factors, that is, telemetry method and power supplying system, are the keys. There are two major technologies to realize real-time geophysical monitoring on a deep-sea floor. The tethered buoy-satellite system is one such technology. Even if a giant buoy system with strong moorings is used to maintain its reliability during extremely rough weather, it may be not strong enough because the area from Mariana Islands to Izu-Bonin islands is a well-known typhoon corridor. Other factors such as antenna direction heading to a stationary satellite, communication method between ocean floor and a surface buoy, and power sources for a bottom equipment, are also difficult tasks to be overcome. During past decades, only a weather buoy, which took measurements at only the ocean surface, has been successful (e.g., McPhaden, 1995; Milburm et al., 1996).

Another approach is to use submarine cable systems. The submarine cable system has long technological history and has been proven in the field (e.g., Shimura, 1984). Although optical fiber submarine cables are one of the most advanced and reliable technologies, the use of such submarine cables is extremely costly compared to free-fall-pop-up OBS systems. Another kind of submarine cable is an analog coaxial cable, which still provide electrical power and real-time data-telemetry similar to optical fiber systems. If real-time measurement is mandatory for a particular observation such as likely for earthquake and tsunami monitoring, submarine cables would be the best choice.

Recently, many submarine cable ocean bottom seismometers have been deployed along the Nankai Trough, the Sagami Trough, and the Japan Trench all within distances of reasonable cable lengths (JMA, 1980; Fujisawa et al., 1986; Urabe and Mizoue, 1996; Eguchi et al., 1997; Kanazawa and Hasegawa, 1997; Kinoshita, 1997). However, the Izu-Bonin and Mariana arcs requires an order of magnitude longer cable and are not practical targets to use a fiber optical system.

During the period from 1960 to 1988, analog coaxial submarine cables were used for telecommunication purposes. In 1964, the first Japan-USA telecommunication submarine cables system, TPC-1, started commercial service. Twelve years later, the second Japan-USA submarine telecommunication submarine cable system, the TPC-2, also started the commercial services in 1976. The numbers of voice channels for such cables was less than 1,000. Due to the rapid development of optical fiber technology and huge demand from international information exchanges, the old analog coaxial submarine cables have been replaced by optical fiber cables, which can provide huge voice or data channels. With the installation of the first Japan-USA optical fiber submarine cable system, TPC-3 (Trans Pacific Cable-3), the TPC-1 ceased 26 years of commercial use in 1990. Following the TPC-1, the TPC-2 system also terminated commercial services in 1994. With the emergence of such a big capacity communication tool, the lives of the remaining analog coaxial submarine cables for commercial use have been shortened.

If we can reuse such resources, real-time geophysical observatories on a deep-sea floor could be realized with high reliability and at a reasonable cost. Based on this idea, scientists in Japan and the USA started to use the former telecommunication cables between Japan and the USA for scientific purposes in 1987 (Nagumo and Walker, 1989; Kasahara, 1990; Kasahara et al., 1990; IRIS, 1992). In 1990, a subsection of the TPC-1 submarine cables, between Ninomiya, Japan and Guam island, was donated to scientific groups of Earthquake Research Institute, University of Tokyo, and IRIS (Incorporated Research Institutions for Seismology) in the USA by former owners such as KDD, Co. Ltd., and AT\&T, Inc. It runs along geophysically important places. It starts at Guam, approaches the Mariana Trough, runs along the forearc slope of the Izu-Bonin Trenches and in the Sagami-Bay, and finally reaches Ninomiya, Japan. In 1996, a subsection of the TPC-2, between Guam and the main island of Okinawa, was donated to Earthquake Research Institute. This cable crosses the Nansei-syoto Trench, the mid Philippine Sea plate, and the south Mariana Trough. These places are also geophysically significant as mentioned earlier.

There are two major projects related to scientific reuse of decommissioned submarine cables in Japan. The GeOTOC (Geophysical and Oceanographical Trans Ocean Cable) project uses the TPC-1 between Guam and Ninomiya (thereafter GeO-TOC). The other effort is the VENUS (Versatile Eco-monitoring Network by Undersea-cable System) project. The VENUS project uses the TPC-2 between Guam and Okinawa (Guam Okinawa Geophysical Cable; thereafter GOGC). In this project, multi-disciplinary observatories will be installed on the forearc of the Nansei-syoto Trench and in the middle of the Philippine Sea plate or near the hot hydrothermal vents in the south Mariana Trough.

\section{Installation of the First Cable OBS Using the GeO-TOC System}

Because some descriptions of the IZU OBS bottom packages in the $\mathrm{GeO}$-TOC project have been given in previous papers (Kasahara et al., 1995; Kasahara et al., 1998), only minimal descriptions of the GeO-TOC system are given in 


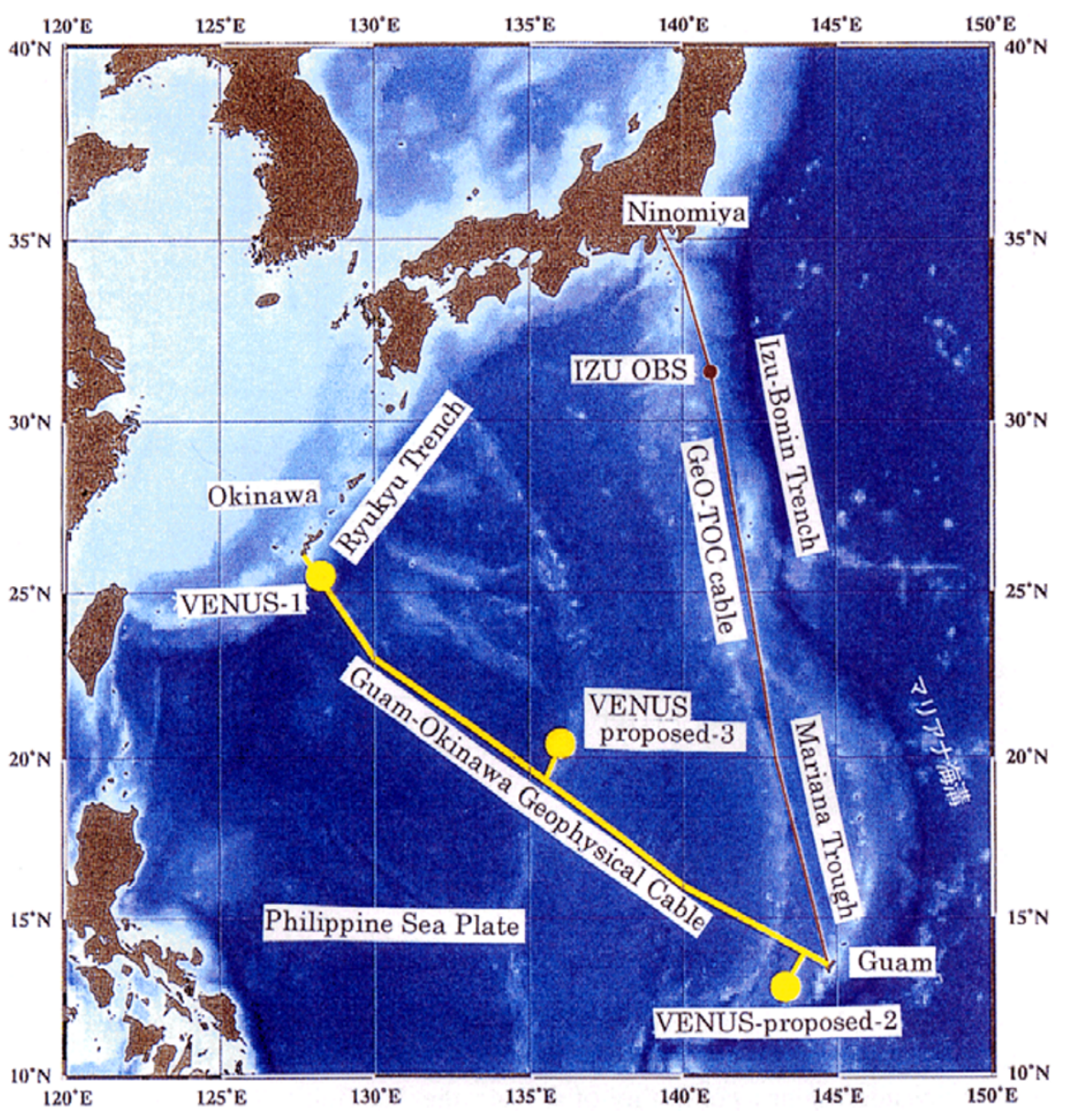

Fig. 1. Cable routes of GeO-TOC (former TPC-1) and GOGC (former TPC-2). The IZU OBS by GeO-TOC and the multi-disciplinary geophysical station off Okinawa by VENUS project are also shown.

this paper.

\subsection{Cable life expectancy, available power, and telemetry}

The length of the GeO-TOC submarine cable is $2,659 \mathrm{~km}$. Figure 1 shows the cable route and the location of IZU OBS. The GeO-TOC system has 74 repeaters and seven equalizers between Ninomiya and Guam (KDD, 1964; U.S. Department of Commerce, 1991). A repeater is an amplifier to compensate for gain-loss caused by submarine cables. An equalizer compensates for miss-matching over the pass-frequency caused by cables and repeaters. The cable length between two adjacent repeaters is $37.08 \mathrm{~km}$ (20 nautical miles). A repeater comprises dual sets of vacuums tube amplifiers, because vacuum tubes were the most reliable electronic devices in early 60's when the system was designed. The first question was on remaining life of the cable system because the official life of the system was 25 years. The design lives of repeaters and equalizers, however, were roughly more than 50 years and the estimated lives of submarine cables were more than the lives of the electronics (Dodeman, personal communication). One of dual amplifier circuits is a set for redundancy. Therefore, the remaining life of the GeO-TOC system could be more than 10 years.

The supply voltage allowance for the TPC-1 system is $6,000 \mathrm{~V}$ DC (KDD, 1964). Because the voltage used in the past was approximately 4,060 $\mathrm{V}$ and $370 \mathrm{~mA}$, an additional $1,940 \mathrm{~V}$ and $370 \mathrm{~mA}$ can be used for instruments and cable loss. If one station uses $30 \mathrm{~W}$, more than 20 stations can be installed along the cable. During commercial use, 138 voice channels were transmitted through the coaxial-cable on a 1-MHz carrier superposed on a high DC voltage. The up-direction (to Guam) used the higher half of $1 \mathrm{MHz}$ and the down-direction (to Ninomiya) used the lower half. Each voice channel used $3 \mathrm{kHz}$ bandwidth. If several voice channels are used for data-telemetry, there is enough capacity for scientific use.

\subsection{IZU OBS}

A new OBS was developed for using analog coaxial submarine cable system (Kasahara et al., 1998). Figure 2 shows the block diagram for sensors and data-telemetry. Special considerations were included in circuit's design. For example, the DC power unit has to be guaranteed under a very slow increase of supply voltage such as $4,170 \mathrm{~V} / 15$ minutes, high resistive voltage, and $370 \mathrm{~mA}$ constant current supply.

Sensors comprise three-axes accelerometers with gimbal, hydrophone, quartz thermometer for external temperature, thermometers for internal temperature, and quartz pressure sensor for external pressure. The minimum resolution of an accelerometer is $100 \mu$ gals at 10 seconds. The frequency characteristics is flat over DC-25 Hz. Twenty-two bits effec- 


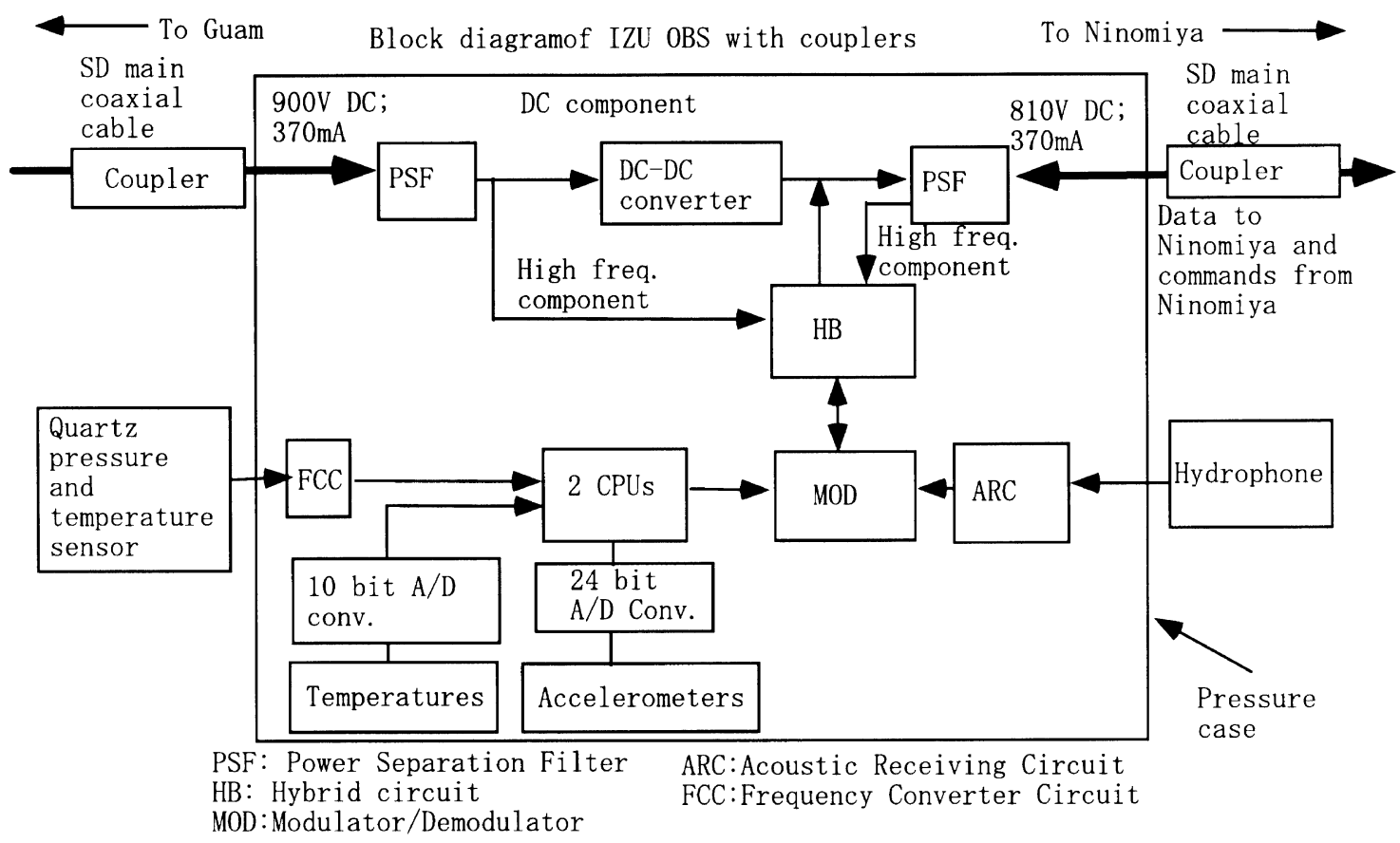

Fig. 2. Block diagram of IZU OBS for sensors and data-telemetry (after Kasahara et al., 1998).

tive resolution with 125 or $62.5 \mathrm{~Hz}$ sampling rate is obtained for accelerometers. The hydrophone signals, however, are transmitted by analog form considering any possibility of a failure of digital circuits, although analog data transmission degrades the quality of data. Two PSFs (Power Separation Filters) for both sides of the high frequency circuit in the instrument are necessary to separate the high DC voltage from the carrier frequency. Data are transmitted to shore by FDM (Frequency Division Multiplexing). Each voice (communication) channel uses $4-\mathrm{kHz}$ frequency bands-width. The IZU OBS, uses only five channels for data and two channels for control commands and initialization of the acquisition system. Each accelerometer signal is transmitted at 9,600 bps. Each $4-\mathrm{kHz}$ channel is modulated by a high-frequency carrier. Control commands for system initialization, gimbal leveling, amplification factor for accelerometers, A/D-reset, and transmission-speed selection are sent from a land terminal to the instrument. The unused broad frequency band is open to any future uses. Instruments are enclosed in a stainless steel pressure case having a repeater-like-shape fitting for deployment by a cable ship deployment.

The location for the first OBS was selected on the forearc slope of the Izu-Bonin Trench to be near active submarine volcanoes, where there is no seismic station nearby as shown in Fig. 3. Myojin-syo is $100 \mathrm{~km}$ and Sumisu Island is $80 \mathrm{~km}$ from the IZU OBS, respectively (see Fig. 3). Myojin-syo has repeated extensive submarine eruptions every year during the past 100 years (Ossaka, 1991). Sumisu Island is nearly submerged and some eruptions have been recognized in the past 100 years (Ossaka, 1991). The IZU OBS can detect the onsets of submarine activities from T-phase observations.

The cable ship KDD Ocean Link deployed the IZU OBS on January 13, 1997. The final location was decided to be midway between two repeaters R14 and R15 for engineering reasons. The instrument was installed 2,708 $\mathrm{m}$ deep on the Izu-Bonin Trench slope. The tentative location is $31^{\circ} 24.62^{\prime} \mathrm{N}, 140^{\circ} 54.33^{\prime} \mathrm{E}$ (Fig. 3). The precise position of OBS will be determined by an air-gun survey in 1998. The DC power of $+4,170 \mathrm{~V}$ and $370 \mathrm{~mA}$ is supplied to the GeOTOC cable from Guam.

Deployment using a cable ship substantially constrained the shape of the seismometer package. Although from the viewpoint of seismology, seismometers are required to be free from cables, the IZU OBS package has submarine cables at both ends of the package. A more ideal installation would be to bury a seismic package in the ocean bottom sediment to be free from bottom currents.

\subsection{Shore station and Tokyo data center}

One of the submarine cable-ends is landed to Ninomiya. Demodulated digital data are input to a data-communicationterminal. The terminal has functions for communication to the bottom equipment through shore receiving and transmitting equipment, communication to ERI Tokyo, digitization of hydrophone data, time-keeping using a GPS clock, datacompression, temporary data stock on a hard disk, and displaying of waveforms. The hydrophone data from the bottom sensors are digitized at 16-bit resolution in this terminal. After adding the digital hydrophone data and time stamps, all data are re-multiplexed in time for data communication to Tokyo. The data rate between Ninomiya and Tokyo is 64 kbps.

The function of the Tokyo terminal is similar to the Ninomiya terminal, except for some functions such as online data link to the ERI seismic network and ftp capability. Control commands are sent in the reverse direction. The capability to control the bottom instrument is different from 


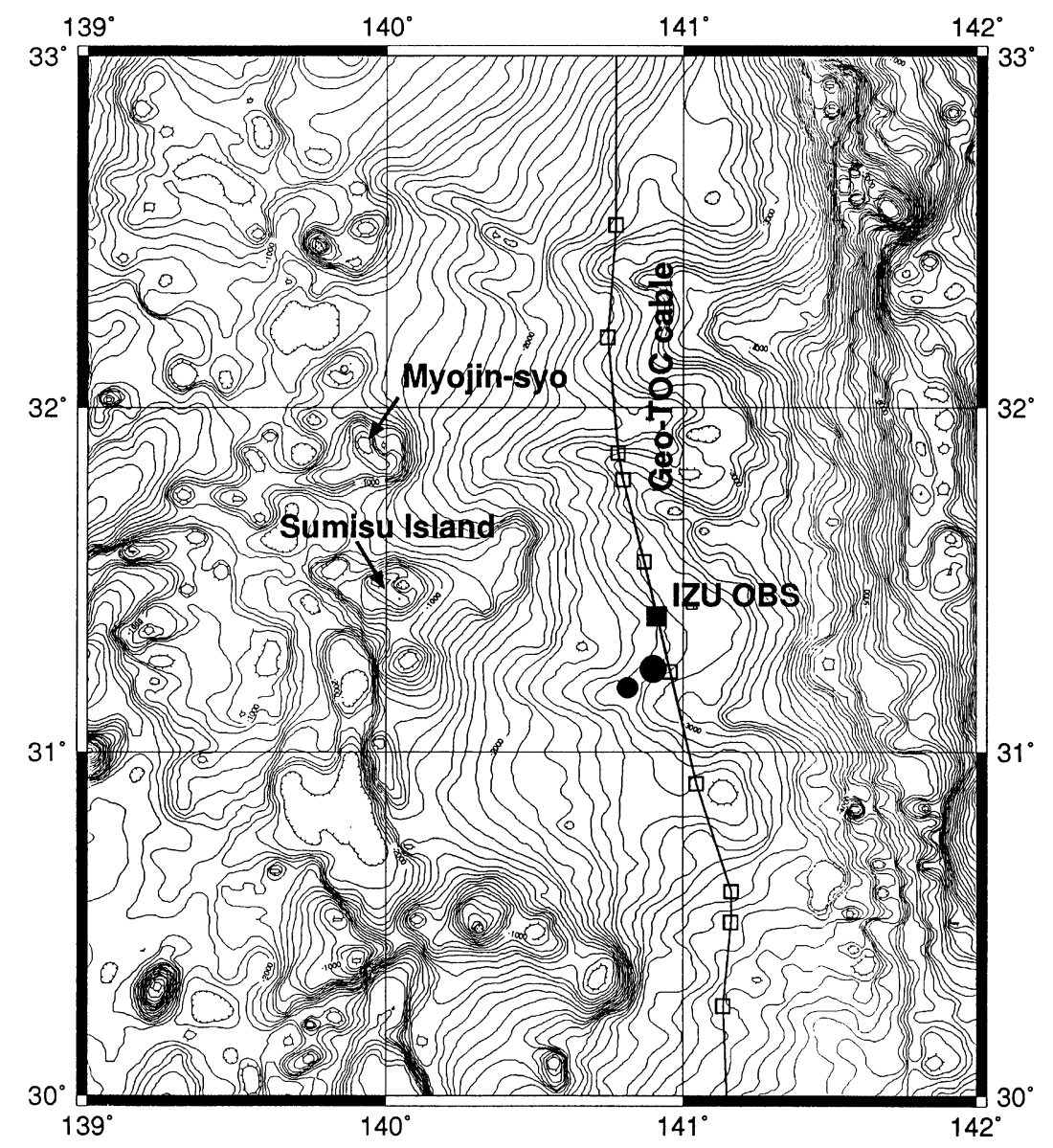

Fig. 3. Detail map of OBS IZU (solid square) and epicenters of the main shock $\left(\mathrm{M}_{\mathrm{f}-\mathrm{p}}=6.4, \mathrm{Mw}=6.1\right.$; large solid circle) and the largest aftershock $\left(\mathrm{M}_{\mathrm{f}-\mathrm{p}}=5.5\right.$; small solid circle) on November 11 and 12, 1997, respectively. Open squares: repeaters and course changes.

other submarine cable OBSs. The other cable OBSs, e.g., Sanriku and east of Izu-Peninsula systems of ERI, were designed only for passive operation.

Since installation, more than one-year passed and continuous data have been saved on MO disks on another computer. The size of one hour of data is approximately $4.5 \mathrm{Mb}$. The IZU data have been regularly processed with the University Micro-earthquake Network to determine hypocenters in Japan since March 1998. The data will be sent to IRIS soon. 3.4 Recent examples obtained by IZU OBS

Recently very interesting records were observed for a Mw 6.1 (Harvard CMT solution) earthquake, which occurred just beneath the IZU OBS $80 \mathrm{~km}$ deep at 08:06 (JST = GMT + 9) on November 11, 1997 (Fig. 4). The accelerometer records show co-seismic offset (Fig. 4(c)) and gradual increase of baseline level (Fig. 4(b)). Because an accelerometer is a kind of tilt-meter (Katao et al., 1990) and the frequency responses of accelerometers are designed to be flat for DC-50 Hz, the above observed changes probably correspond to tilt movements. The maximum change of EW component was 8 gals for co-seismic and 0.2 gals during an hour, half an hour after the main shock onset. On the pressure channel shown in Fig. 5, a change equivalent to negative 50$\mathrm{cm}$ sea-level change was observed one minute after the main shock onset, although seawater temperature and acceleration did not show any significant changes at a time corresponding to the sea-level change. If a slip-down movement of the OBS package caused the pressure change, the accelerometers should show positive large signals. During the main shock onset, accelerometers showed 100-gal amplitude and the pressure gauge showed negative $10-\mathrm{cm}$ sea-level change. This suggests that the response of the pressure sensor is less than 10 seconds, which is the sampling rate. These anomalous observations suggest local sources such as caused by a deep-sea landslide induced by the earthquake although it is difficult to completely deny the possibility that these changes were generated by an extremely local occurrence such as instrument package rotation. The above observation suggests a high possibility of detecting silent earthquakes or earthquake precursors if they exist.

Figure 6 shows an example of pressure and temperature records of IZU OBS over one day. During the day of May 21, 1997, pressure change was approximately $\pm 50 \mathrm{~cm}$ and the temperature change was approximately $0.05^{\circ} \mathrm{C}$. The pressure change shows clear 12 hours periodicity suggesting an ocean tide origin, and the temperature is inconsistent with the pressure change. The discrepancy between pressure and temperature suggests that the temperature change was not directly related to the ocean tide, but tide-independent deep-sea current may cause it. 


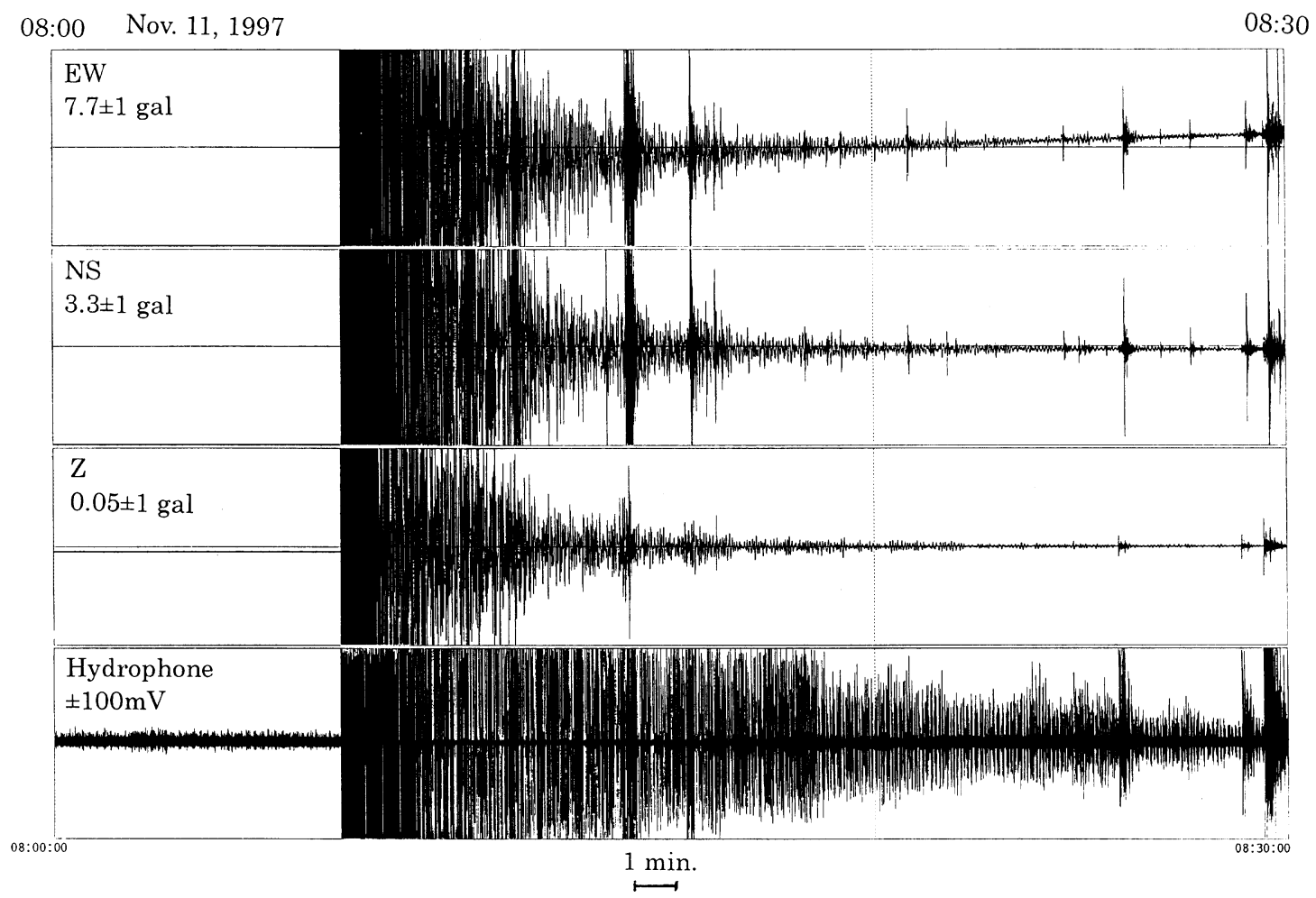

(a)

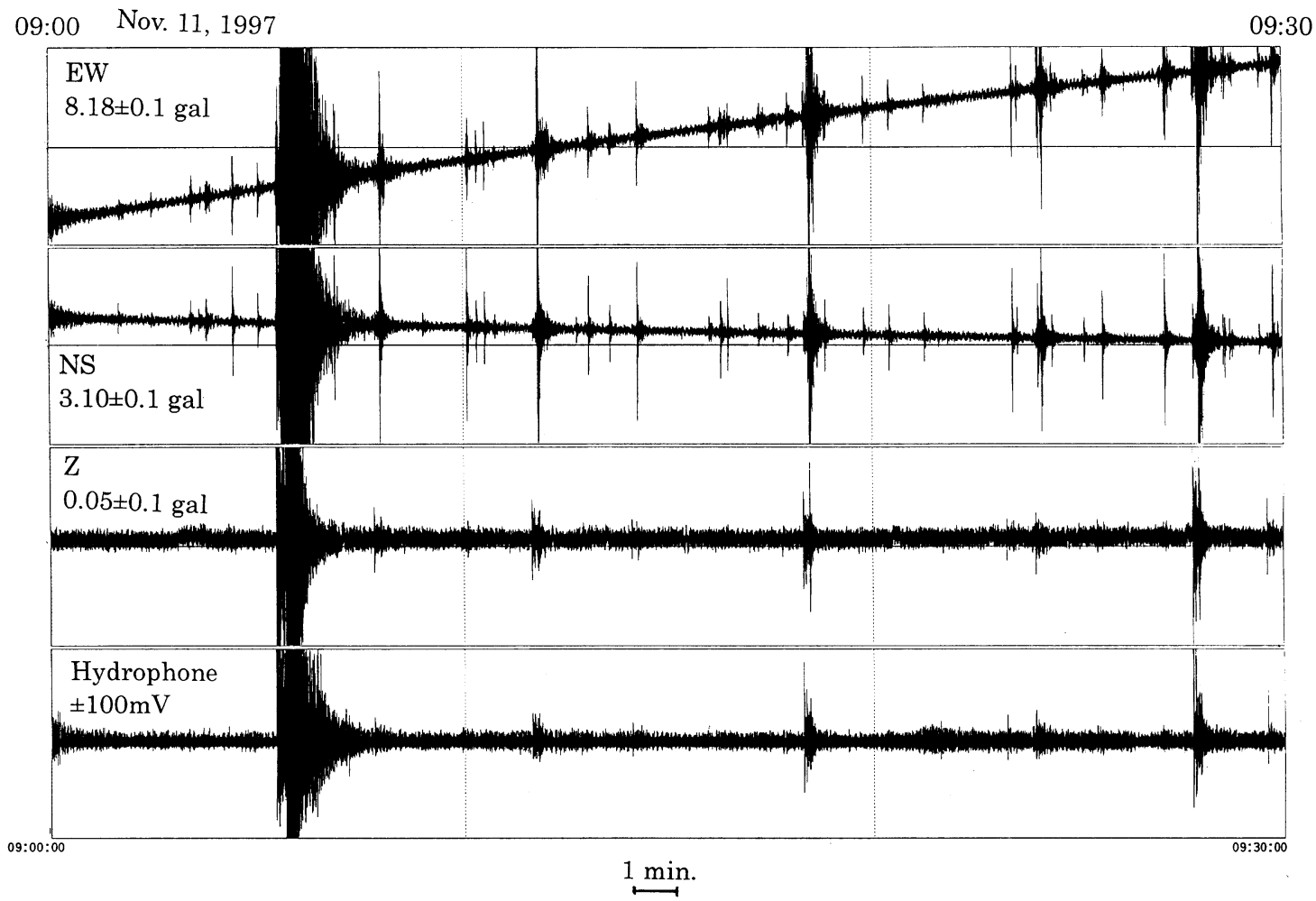

(b)

Fig. 4. An example of seismic record for a Mw 6.1 (Harvard CMT solution) nearby earthquake which occurred 80 km deep at 08:06 (JST = GMT + 9) on November 11, 1997. Earthquake epicenter of the main shock is shown in Fig. 3. (a) 08:00-08:30 JST; (b) 09:00-09:30 JST; (c) Co-seismic tilt change during 08:06-08:11 JST. Note: 0-level of each sensor before earthquake was approximately 0 gal, but it was shifted to 8.0, 3.0 and 0.05 gals after the main shock for EW, NS and Z components, respectively. 


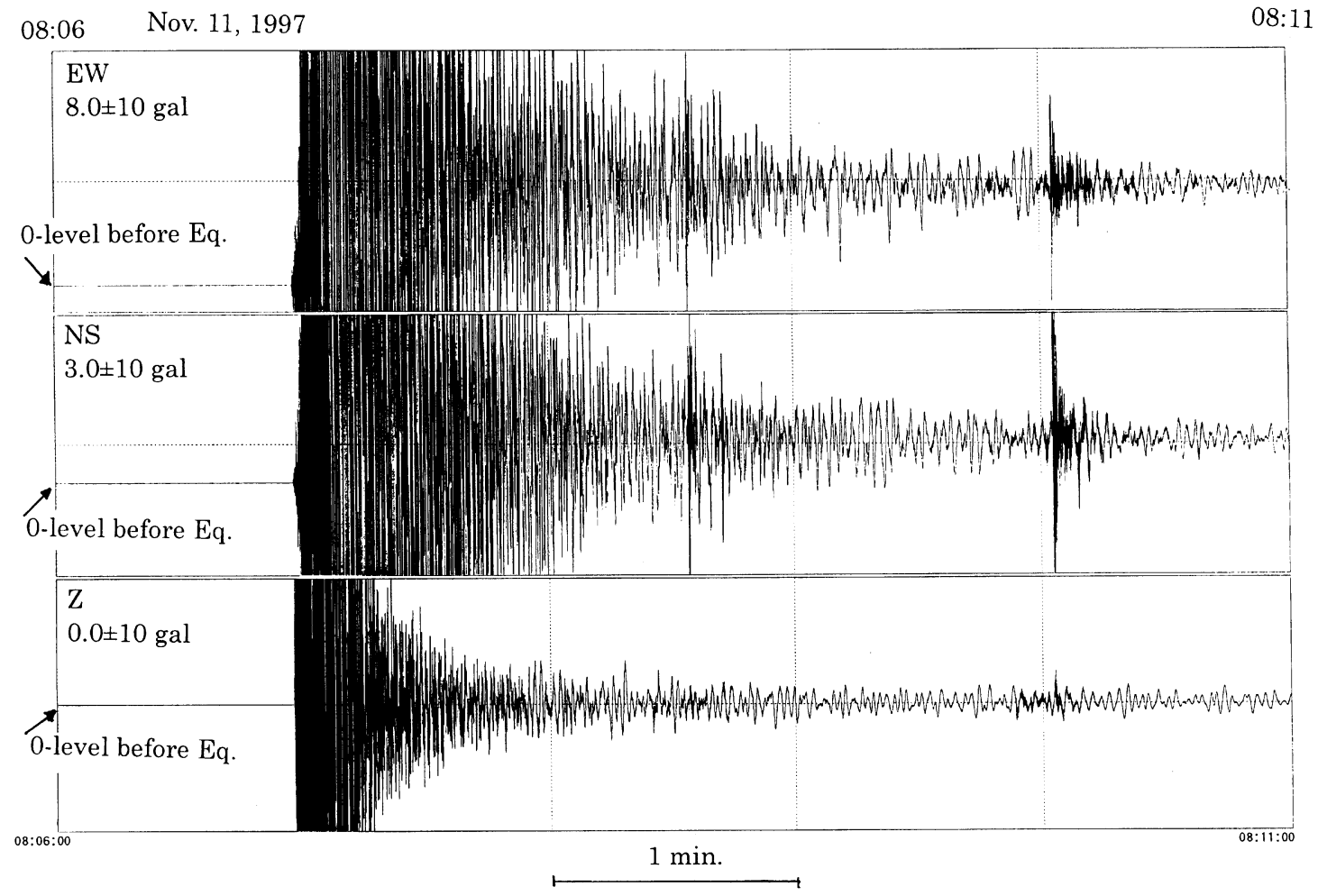

(c)

Fig. 4. (continued).

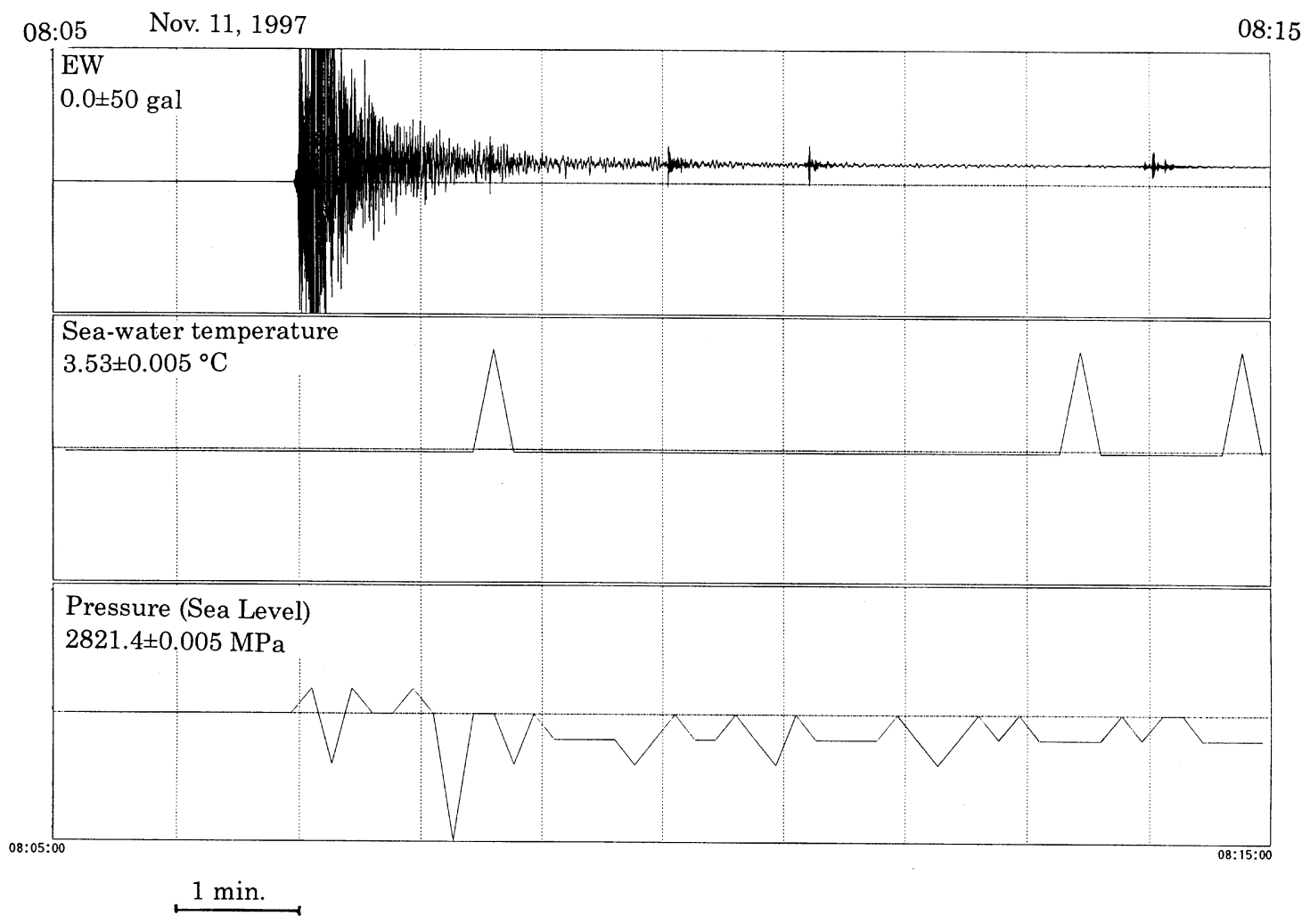

Fig. 5. Records of EW component of accelerometer, sea-water temperature and pressure (sea-level) change during the Mw 6.1 earthquake and its aftershocks (08:05-08:15 JST, on November 11, 1997). 


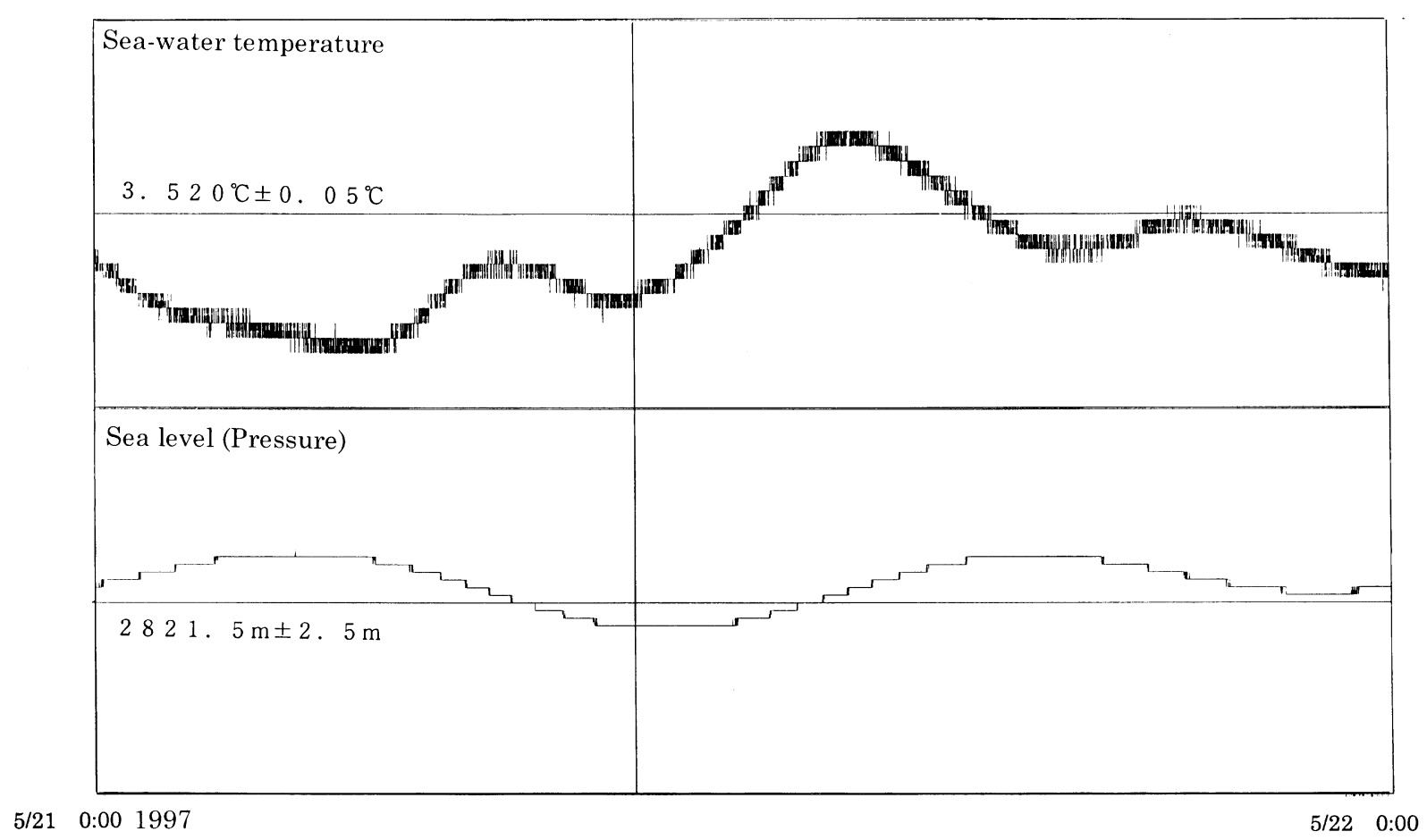

Fig. 6. One-day record of sea-level and temperature changes obtained with a pressure gauge and a temperature probe. Although the sea-level change shows a 12-hour ocean-tide, the temperature variation does not have a linear correlation with pressure variation.

\section{Installation of Multi-Disciplinary Geophysical Observatory Using GOGC System}

The TPC-2 (KDD, 1976) runs through the middle of the Philippine Sea plate from Guam to Okinawa, Japan. The TPC-2 Guam-Okinawa section is called GOGC (GuamOkinawa Geophysical Cable).

The objective of the VENUS project is to construct multidisciplinary stations using the GOGC for studying deep-sea environmental changes around the Philippine Sea plate. The project has a five-year plan starting from the fiscal 1995. Nine institutions are working jointly on this: JAMSTEC (JApan Marine Science and TEchnology Center), Hydrographic Department of Maritime Safety Agency, Meteorological Institute of JMA, Earthquake Research Institute of University of Tokyo, Geological Survey of Japan, Communications Research Laboratory, Electro-technical Laboratory, and KDD Research Laboratory.

The VENUS project is divided into two phases: phase I between fiscal 1995 and 1997 and phase II between fiscal 1998 and 1999. Under the plan, during phase II, a multidisciplinary observatory will be installed 2,200 m deep on the landward slope of the Nansei-syoto Trench.

\subsection{GOGC and the VENUS design policy}

The GOGC (Fig. 1) connects the shore station in Okinawa and the sea-grounding in the Mariana Trough, because the GOGC was re-grounded to sea-grounding in the Mariana Trough in 1996 at the request of AT\&T. The cable length of the Guam-Okinawa section was $2,527 \mathrm{~km}$. There were 141 repeaters and six equalizers. Re-grounding reduced it by $130 \mathrm{~km}$ (70 nautical miles) from the Guam-end. The system uses so-called 1.5" SF coaxial-cables whose outer diameter is $44.5 \mathrm{~mm}$. The attenuation in the cable is $4 \mathrm{~dB} / \mathrm{nm}$ at
$6 \mathrm{MHz}$. Each repeater, which uses transistors for components, has $40 \mathrm{~dB}$ gain and requires 13 Volts at $136 \mathrm{~mA}$ for power dissipation to compensate for attenuation due to the cables. The $+1,080 \mathrm{~V}$ DC from Okinawa and $-1,080 \mathrm{~V}$ DC from Guam were supplied to the cables with $136 \mathrm{~mA}$ constant currents during commercial use. In the VENUS project, electric power has to be supplied to cables only from Okinawa because the former Guam cable-end is now no longer the landing site. The system has the capability of a single power supply, which was provided during the commercial operation for test purposes. The maximum supply voltage to the TPC-2 cables was designed to be $4,500 \mathrm{~V}$. Because it is necessary to reserve $2,360 \mathrm{~V}$ for the cable systems considering the $130 \mathrm{~km}$ shortened-part and geomagnetic induced voltage change, rest of voltage, $2,140 \mathrm{~V}$ can be used for scientific instruments. This corresponds to $291 \mathrm{~W}$. If the efficiency of the $\mathrm{DC} / \mathrm{DC}$ converter is $60 \%, 175 \mathrm{~W}$ can be used for the instruments. If three bottom laboratories share this maximum power, approximately $58 \mathrm{~W}$ is the allowable limit for one site.

The TPC-2 used two carrier frequency bands: 312-3,036 $\mathrm{kHz}$ (low-band) and 3,412-6,136 kHz (high-band). Each carrier band allowed 845 voice channels using $3 \mathrm{kHz}$ bandwidth. There are two typical uses of the frequency bands, that is, $4 \mathrm{kHz}$ bandwidth voice channels for single data stream and wide bandwidth for multi-component data. In the first VENUS station, $240 \mathrm{kHz}$ bandwidths are used as described in the later section.

\subsection{Outline of VENUS system}

Figure 7 shows an overview of the VENUS system. The VENUS multi-disciplinary geophysical observatory will be deployed $50 \mathrm{~km}$ from the mainland of Okinawa in fall of 


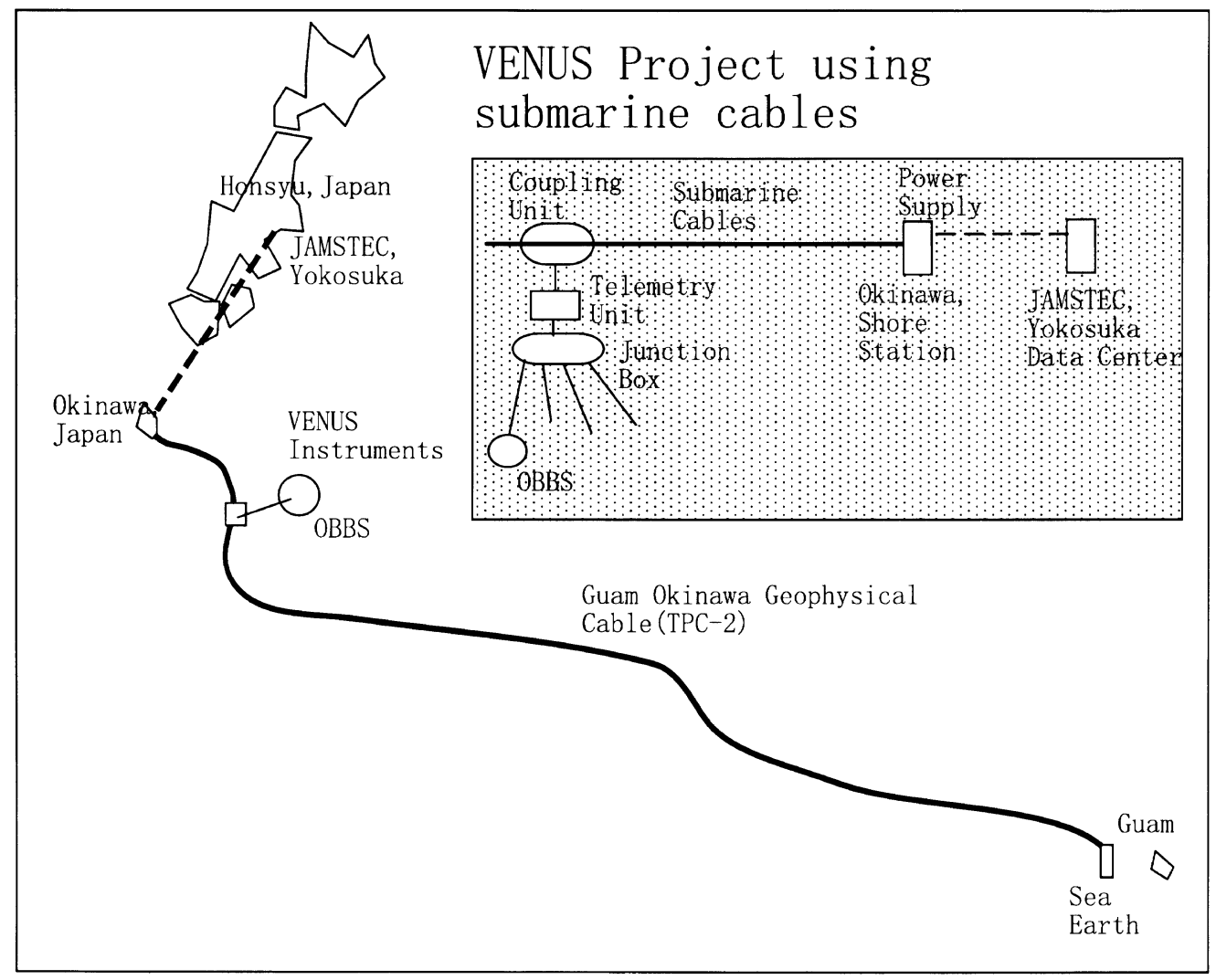

Fig. 7. Overview of the VENUS system from bottom to data center.

1998. It will be located $2,200 \mathrm{~m}$ deep on the landward slope of the Nansei-syoto Trench. The system comprises bottom sensors, junction box, data-coupling unit, data-telemetry unit, main coaxial cables (GOGC), receiving and telemetry unit at the Okinawa shore station, sea-grounding, OkinawaYokosuka communication unit and Yokosuka data center. The observatory comprises seven deep-sea instrument units (Fig. 8) and one land measurement: broadband seismometers, tsunami pressure sensor, hydrophone array, multi-sensor unit, geodetic instruments, geoelectric and geomagnetic instruments, acoustic link and geo-potential measurement for the whole cable length.

The total power dissipation caused by sensors, datacoupling unit, and data-telemetry unit is approximately $53.5 \mathrm{~W}$, which is less than the allowable limit for the power supply. Two stages of DC/DC conversions are used. In the first stage, DC $100 \mathrm{~V}(0.5-1 \mathrm{Amp}$.) is created by $900 \mathrm{~V}$ and $136 \mathrm{~mA}$ drops from the cable power supply. In the second stage, $24 \mathrm{~V}$ DC (0.7-1.4 Amp.) is created using the above $100 \mathrm{~V}$ DC. To supply $136 \mathrm{~mA}$ constant currents for the cable, a dummy load in the data-coupling unit radiates heat if current is less than $136 \mathrm{~mA}$. Also, a $1 \mathrm{Amp}$, maximum rush current is allowed for each sensor. Instruments should be turned on and off one at a time to avoid large current flows. All pressure housings for bottom units are made of titanium to resist corrosion during the long observation period.

\subsection{Multi-disciplinary sensors}

This section provides a brief outline of the sensors (Fig. 8). The OBBS (Ocean Bottom Broadband Seismometer)
(Fig. 9) uses "Guralp CMG-1T" three axes broadband seismometers in gimbal (Kasahara and Sato, 1997). Three 24bit A/D converters and one 16-bit microprocessor are used. In addition to broadband seismometers, there are temperature sensors to measure on-board temperature, magnetic compasses and two-axes tilt-meter to measure the positions of seismometers. From land, lock-unlock, leveling, masscenter, and CPU reset can be controlled. Sensitivity of broadband seismometers is $1 \mathrm{~V} /(\mathrm{m} / \mathrm{sec}$.) over $360-0.1$ seconds. The sampling rate is $100 \mathrm{~Hz}$. Power dissipations during observation and control are $130 \mathrm{~mA}$ and $150 \mathrm{~mA}$ at $24 \mathrm{~V}$ $\mathrm{DC}$, respectively. OBBS instruments are enclosed in a titanium sphere with a $50-\mathrm{cm}$ diameter. Data are sent to land at $19.2 \mathrm{kbps}$. Only the OBBS unit among many VENUS instrument units will be carried and installed by the manned submersible Shinkai 6500.

The tsunami gauge uses a quartz pressure sensor and the resolution of sea-level change is $0.5 \mathrm{~mm}$. Because the quartz pressure sensor depends strongly on temperature, temperature correction is applied to the measured value.

The multi-sensor unit (Iwase et al., 1997; Momma et al., 1997) has short period seismometers, single hydrophone, nephelometer, digital still camera, CTD, current meter, and sub-bottom temperature probe. All sensors are mounted in one frame, but the sea-bottom temperature probe will be taken out and put into the sediment.

The hydrophone array (Furukawa et al., 1997) is composed of five single hydrophones with a $700 \mathrm{~m}$ spacing. The total cable length of the hydrophone array is $3,000 \mathrm{~m}$. The 


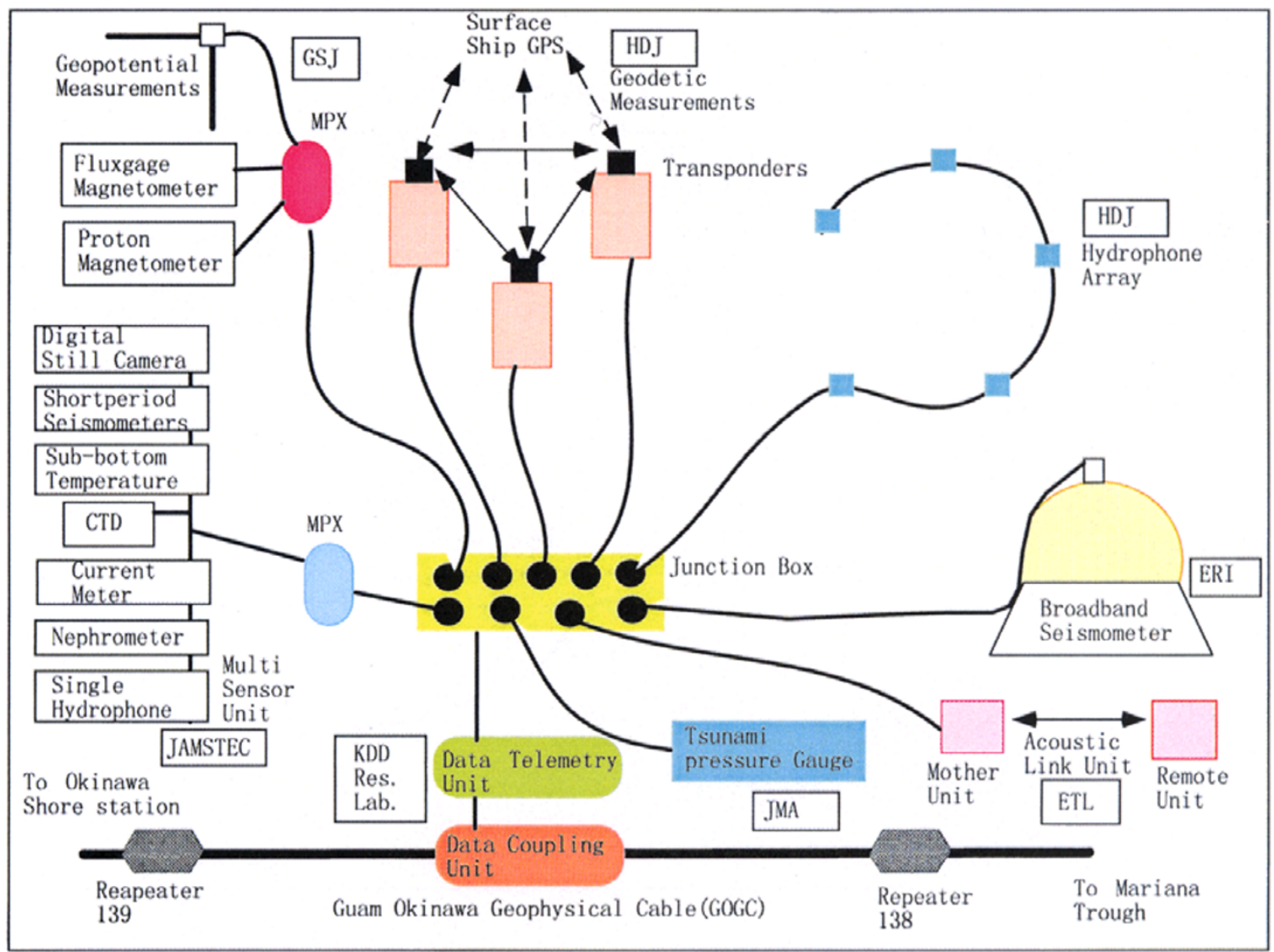

Fig. 8. Deep-sea bottom system. The bottom system comprises data-coupling unit, data-telemetry unit, junction box and seven sensor units.

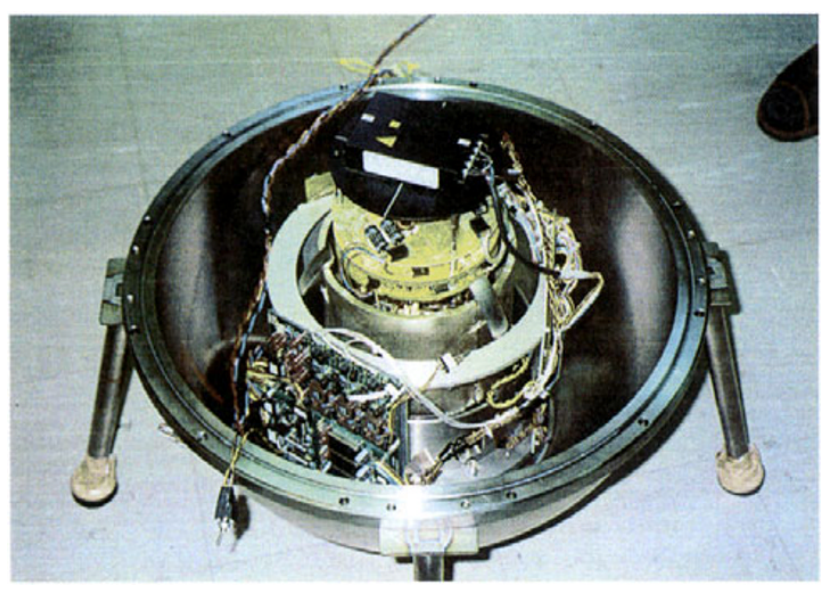

Fig. 9. Photograph of OBBS (Ocean Bottom Broadband Seismometer) in a titanium sphere.

sensitivity of a hydrophone is $-183 \mathrm{dBV} / \mu \mathrm{Pa}$. Although hydrophone signals are digitized by 20 -bit $\mathrm{A} / \mathrm{D}$ converters with a $500 \mathrm{~Hz}$ sampling rate, only 16 bits will be transmitted to shore. The selection of 16 bits among 20 bits can be made using control commands. The hydrophone array could detect sounds from sources such as submarine volcanic eruptions, earthquakes, and whales. Myojin-syo and other submarine volcanoes located along the Izu-Bonin arc are good candi-

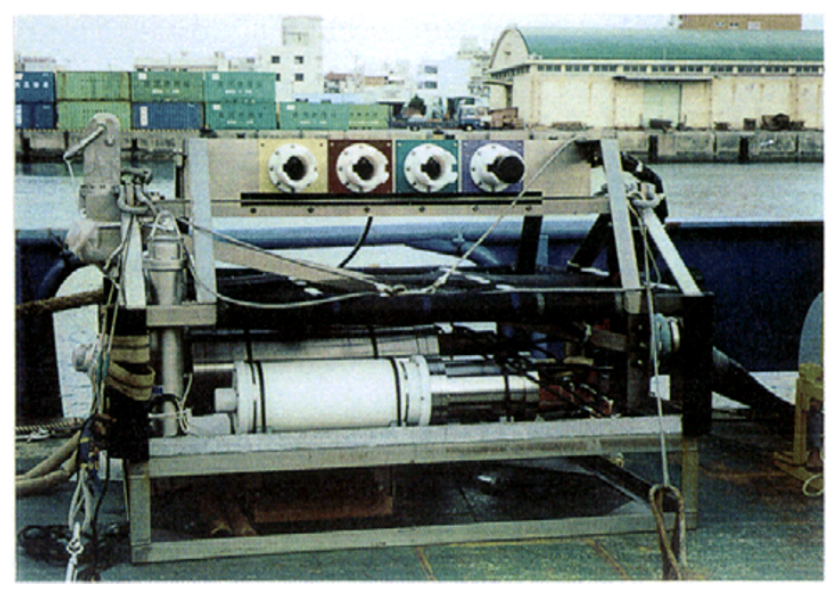

Fig. 10. Photograph of junction box.

dates as sound sources for the hydrophones. The hydrophone array might determine direction and position of these sound sources. Several species of whale family might generate voice sounds that can be detected by the hydrophone array (Miyazaki and Nakahara, 1997).

The geodetic changes are acoustically determined in two ways: baseline measurements between two units, and distance measurements between the surface ship position determined by three GPSs and three bottom units (Nagaya and 
Yabuki, 1997). The cable length between one bottom unit and the junction box is approximately $1 \mathrm{~km}$. The bottom units use GPS time signals as an accurate time standard. The estimated accuracy of geodetic measurements will be a few centimeters, which may be the detectable crustal deformation at the landward slope of trenches.

The geoelectric and geomagnetic unit (Miyazaki et al., 1997) comprises proton magnetometer, flux-gate magnetometers, and geo-potentiometers. The distance of each geopotential measurement is $10 \mathrm{~m}$. The sensitivities of proton magnetometer, flux-gate magnetometers, and geo-potentiometers are $0.1 \mathrm{nT}, 0.01 \mathrm{nT}$, and $32 \mu \mathrm{V} / \mathrm{m}$, respectively.

Acoustic data-link unit comprises communication instrument attached to the junction box and remote instrument. Data and commands are exchanged between the two instruments through an acoustic link. The data rate of 9,600 bps will be obtained by this acoustic link using QPSK (Quad Phase Shift Key) method within 1,000 m distance at seafloor.

The geo-potential measurements using the whole length of the GOGC, similar to geo-potential measurements using TPC-1 (e.g., Kasahara et al., 1995), are also done as a part of the VENUS project. A geomagnetic field induces the electrical potential along the coaxial-cable. Using this potential change, the electrical conductivity distribution in the Earth and solar weather has been studied.

\subsection{Junction box, data-telemetry unit, and data- coupling unit}

This section describes junction box, data-telemetry unit, and data-coupling unit (Shirasaki et al., 1997).

Data from each sensor unit comes to the junction box (Fig. 7) which has nine penetrators or so-called ROV undersea matable connectors. The ROV connectors allow plugin and plug-out at deep-sea areas with the assistance of a manned submersible or a ROV. A waterproof cable connects an instrument to the junction box (Fig. 10).

Using the data-telemetry unit, instrument data except hydrophone array, are multiplexed and sent to shore using a $240 \mathrm{kHz}$ carrier bandwidth (so called SG, Super Group). The use of the SG bandwidth enables us to use the pervious TPC-2 equipment in Okinawa and it helps to decrease total costs. The transmission rate for this channel is $96 \mathrm{kbps}$. Each instrument, however, uses a particular transmission rate, e.g., $19.2 \mathrm{kbps}$ for the broadband seismometers, $1.2 \mathrm{kbps}$ for the tsunami sensor, etc. Hydrophone data are independent from other data and use one $240 \mathrm{kHz}$ bandwidth at a transmission rate of $96 \mathrm{kbps}$. Each data line has enough redundancy for the transmission rate. The data-telemetry unit also receives control commands and time-marks from shore. A GPS clock at the shore station generates time marks. Control commands for a particular sensor-unit have an ID and the data-telemetry unit identifies the ID and distributes the commands to the appropriate sensor-unit. Instruments are turned on and off one at a time. If one instrument is not functioning correctly, the user can shut it down.

The data-coupling unit comprises two PSFs and a DC/DC converter. The PSFs separate the high-voltage DC component from high-frequency carriers, and mix high frequency carrier with the DC component again.

Instruments will occupy an area with a radius of approx- imately $1-\mathrm{km}$ around the junction box. The junction box, the data-coupling unit, and the data-telemetry unit will be installed midway between two repeaters R139 and R138. The target location, $50 \mathrm{~km}$ south of Okinawa main island, is $25^{\circ} 44^{\prime} \mathrm{N}$ and $128^{\circ} 02.5^{\prime} \mathrm{E}$ at $2,200 \mathrm{~m}$ deep.

Before deployment, the whole electronic system in the VENUS was successfully tested twice at the JAMSTEC laboratory in the fall of 1997. All instruments and all equipment between bottom units and the data terminal were connected in these tests. Although some defects were found during the exercises, they were all fixed during the exercises. All pressure cases were tested under high pressure.

\subsection{Shore facility at Okinawa and data center at Yokosuka}

A shore station is located in the building of KDD Okinawa station. Most of the receiving/transmission units at the shore station were obtained from the previous ones used by the TPC-2 system. The shore equipment comprises PSF, HFLs (High-Frequency Lines), SG (Super Group) bank, modulator, demodulator, power supplies, GPS clock and data communication system among ocean bottom, shore and data center. The HFL unit makes frequency misfit adjustments over the cable system. The SG bank takes out a particular frequency $(\mathrm{SG})$ band from the whole carrier frequency width. The DC component of the main cable separated by PSF is grounded to the sea-grounding at the shore station.

The data link between Okinawa and Yokosuka is $128 \mathrm{kbps}$ using a commercial data line. Data from bottom instruments passed through the shore station are stored in a $64 \mathrm{~Gb}$ disk array of the VENUS data terminal in Yokosuka. A satellite communication link between Okinawa and ERI-Tokyo is also planned.

\subsection{Plan for field works at deployment}

The manned submersible Shinkai 6500 practiced its approach to the GOGC cable at depth of 4,200 m in 1996 and simulated cutting cables. A manipulator of Shinkai 6500 easily lifted the cables. The ROV connectors were developed by Ocean Design Inc. for this project and they were tested by JAMSTEC in situ. A cable cutter and a cable gripper equipped on Shinkai 6500 were developed for the VENUS (Kawaguchi et al., 1998). The route of the GOGC cables at the target site 2,200 m deep was identified at more than 20 locations by the deep-tow camera of $\mathrm{R} / \mathrm{V}$ Yokosuka in February 1998. The GOGC cables were found to be laid on sediments with thin sediment covers.

A deployment method proposed by Momma et al. (1997) is as follows. Instruments, other than broadband seismometers, will be installed by the deep-tow of R/V Kaiyo. The manned submersible Shinkai 6500 will carry the broadband seismometers. The Shinkai 6500 will cut and grip the cable at the bottom, and another boat M/S Kosin-maru will retrieve the cut-end on board and splice the cable-end to the data-coupling unit. One female coaxial-connector will also be attached to the data-coupling unit. The data-coupling unit should be connected to the data-telemetry unit and the junction box on board of Kosin-maru, and will be deployed in the sea. The Kosin-maru will deploy all of them in the sea. The other cable-end will also be retrieved on board Kosin-maru and a male deep-sea coaxial-connector will be attached to the end. The Shinkai 6500 will connect the male and female 
coaxial-connectors of the cable-end and the data-coupling unit at the ocean floor. Either Shinkai 6500 or ROV Kaiko on board of $\mathrm{R} / \mathrm{V}$ Kairei will connect sensors to the ROV connectors on the junction box.

\section{Summary}

A submarine cable OBS (named IZU OBS) was installed on the landward slope of the Izu-Bonin Trench in the GeOTOC project, using the decommissioned submarine telecommunication cable TPC-1. The IZU OBS has three axes accelerometers, analog hydrophone, pressure gauge, and temperature probes as sensors. The installation of IZU OBS proved the great possibilities in geophysical use of similar submarine cables for ocean bottom measurements in realtime. During a Mw 6.1 earthquake, which occurred just below the station at $80 \mathrm{~km}$-deep in 1997, accelerometers showed co-seismic and gradual changes after the main shock onset. The pressure sensor showed $50-\mathrm{cm}$ sea-level change one minute after the main shock onset, but this does not correspond to seismic phases and temperature change. These observations suggest some causes of such changes other than instrument rotation, and the strong possibility detecting silent earthquakes or earthquake precursors if they exist.

A new breakthrough technology was developed to enable multi-disciplinary observations on a deep-sea floor in the VENUS project. The system also uses a decommissioned submarine cable. One multi-disciplinary geophysical station will be deployed soon on the landward slope of the Nanseisyoto Trench. This might be the first to integrate a number of sensors of various types at one location. It will also prove the usefulness of decommissioned submarine cables for geophysical deep-sea observations. The future results might reveal various phenomena occurring at the subduction zone and rifting backarc basins using multi-component measurements.

Coaxial telecommunication cables are now being replaced by optical fiber technologies. ERI already uses cables such as GeO-TOC, VENUS, and JASC (Japan Sea Cable between Naoetsu and Nakhotka) for geophysical measurements and plans to use Okinawa-Ninomiya cable and Japan-China (Amakusa-Shanghai) cable for further studies. Ocean Research Institute, University of Tokyo, will use Japan-Korea cable (Hamada-Pusang), OKITAI (Okinawa-Taiwan), and OLUFO (Okinawa-Luzon, Philippine) for an ocean circulation study.

In the U.S.A., there is a similar project, called $\mathrm{H} 2 \mathrm{O}$ (Hawaii-2 Observatory) (Chave et al., 1997) as Japanese GeO-TOC and VENUS. The $\mathrm{H} 2 \mathrm{O}$ project will use the former HAW-2 cable between Hawaii and the West Coast of the U.S.A.

Now we are at the dawning of technical break-through in geophysical measurements under the sea.

Acknowledgments. The GeO-TOC project is supported by the Ministry of Education, Science, Culture and Sports, Japan. The VENUS project is supported by the Science and Technology Agency, Japan. The authors express their great thanks to the officers in these agencies for their valuable assistance during our programs. The authors also thank the staff of KDD Co. Ltd. for their great help in carrying out these projects. The authors give their thanks to T. Yukutake, S. Nagumo, and S. Uyeda (Professors of Emeritus,
University of Tokyo) for their continuous encouragement during the cable projects. Drs. H. Utada, T. Kanazawa and M. Yamano (Professors, University of Tokyo) and H. Kinoshita (JAMSTEC) are also greatly thanked for their great assistance. Our U.S. partners also greatly helped our projects.

\section{References}

Chave, A., R. Butler, R. A. Petitt, Jr., D. R. Yoerger, F. B. Wooding, A D. Bowen, L. E. Freitag, J. Catipovic, F. K. Duennebier, D. Harris, A H. Dodeman, and S. T. Brewer, H2O: The Hawaii-2 Observatory, in Proceedings of International Workshop on Scientific Use of Submarine Cables, pp. 114-115, Okinawa, Japan, 1997.

Craig, Y., K. Horiba, A. Farley, J. A. Welhan, K.-R. Kim, and R. N. Hey, Hydrothermal vents in the Mariana Trough: results of the first ALVINE dives, EOS Trans. AGU, 68, 1531, 1987.

Eguchi, T., Y. Fujinawa, E. Fujita, S. Iwasaki, I. Watanabe, and H. Fujiwara, An observation network of ocean-bottom seismometers deployed at the Sagami Trough subduction zone, in Proceedings of International Workshop on Scientific Use of Submarine Cables, pp. 143-146, Okinawa, 1997.

Fujisawa, K., S. Tateyama, and J. Funasaki, Permanent ocean-bottom earthquake and tsunami observation system off the Boso Peninsula, Weather Service Bull., 53, 127-166, 1986 (in Japanese)

Furukawa, H., A. Nishizawa, and A. Asada, Monitoring system for submarine volcanic activities, in Proceedings of International Workshop on Scientific Use of Submarine Cables, pp. 153-156, Okinawa, 1997.

Gamo, T., H. Chiba, P. Fryer, J. Ishibashi, T. Ishii, L. E. Johnson, K. Kelly, H. Masuda, S. Ohta, A.-L. Reysenbach, P. A. Rona, T. Shibata, J. Tamaoka, H. Tanaka, U. Tsunogai, T. Yamaguchi, and K. Fujioka, Mariana 1992 diving surveys by "Shinkai 6500" (Y920cruise): Revisits to the MidMariana hydrothermal area and discovery of hydrothermal vents in the southern Mariana region, JAMSTEC Deep Sea Res., 10, 154-162, 1994.

Grand, S. R., D. van der Hilst, and S. Widiyantro, Global seismic tomography: A snapshot of convection in the Earth, Geol. Soc. Am., Today, 7, No. 4, 1-7, 1997.

Hawkins, J. W., P. F. Lonsdale, J. D. Macdougall, and A. M. Volpe, Petrology of the axial ridge of the Mariana Trough backarc spreading center, Earth Planet. Sci. Lett., 100, 226-250, 1990.

IRIS Steering Committee for scientific use of submarine cables, Scientific use of submarine telecommunication cable, EOS Trans. AGU, 73, 97 100-101, 1992

Ishii, T., P. T. Robinson, H. Maekawa, and R. Fiske, Petrological studies of peridotites from diapiritick serpentine seamounts in the Izu-OgasawaraMariana forearc, Leg., 125, Proc. Ocean Drill. Proc., Scientific Results, 125, 445-485, 1992 .

Iwase, R., H. Momma, and K. Kawaguchi, The real-time and long-term deep-sea floor observation using the multisensor, in Proceedings of International Workshop on Scientific Use of Submarine Cables, pp. 160-162, Okinawa, 1997.

JMA Seismology and Volcanology Department, Permanent ocean bottom seismograph observation system, Technical Rep. Meteorological Res. Inst., 4, 1-233, 1980 (in Japanese).

Kanazawa, T. and A. Hasegawa, Ocean bottom observatory for earthquakes and Tsunami off Sanriku, north-eastern Japan using submarine cable, in Proceedings of International Workshop on Scientific Use of Submarine Cables, pp. 208-209, Okinawa, 1997.

Karig, D. E., Structural history of the Mariana island arc system, Geol. Soc. Am. Bull., 82, 323-344, 1971.

Karig, D. E., R. N. Anderson, and L. D. Bibee, Characteristics of back arc spreading in the Mariana Trough, J. Geophys. Res., 83, 1213-1226, 1978

Kasahara, J., Engineering models of TPC-1 project, in Workshop on Scientific Use of Submarine Cables, edited by A. Chave and T. Pyle, pp. 266273, Joint Oceanographic Inst., Washington, D.C., 1990.

Kasahara, J. and T. Sato, Broadband seismic observation in VENUS project, in Proceedings of International Workshop on Scientific Use of Submarine Cables, pp. 192-196, Okinawa, Japan, 1997.

Kasahara, J., Y. Hamano, and T. Yukutake, Outline of earth science studies using the Trans Pacific Cable, Monthly Kaiyo, 22, 447-451, 1990 (in Japanese).

Kasahara, J., L. Kong, S. Koresawa, C. Igarashi, T. Yamaguchi, M. Suzuki, and R. Feng-Lu, Seismic observation at the Mariana trough at $18^{\circ} \mathrm{N}$ and its relation to the detailed bathymetry, Preliminary Report of the HakuhoMaru Cruise KH92-1, Ocean Research Institute, Univ. Tokyo, 77-98, 1993.

Kasahara, J., T. Sato, and K. Fujioka, Intensive thermal upwelling at 
seamount in the south Mariana Trough observed by ocean bottom seismic instruments using "Shinkai 6500" submersible, JAMSTEC Deep Sea Res., 10, 163-174, 1994

Kasahara, J., H. Utada, and H. Kinoshita, GeO-TOC project-Reuse of submarine cables for seismic and geoelectric measurements, J. Phys. Earth, 43, 619-628, 1995.

Kasahara, J., H. Utada, T. Sato, and H. Kinoshita, Submarine cable OBS using a retired submarine telecommunication cable: GeO-TOC program, Phys. Earth Planet. Inter., 108, 113-127, 1998.

Katao, H., J. Kasahara, and S. Koresawa, Seismic observation using inertial navigation servo accelerometers for application to the broad-band ocean bottom seismometers, Bull. Earthq. Res. Inst., Univ. Tokyo, 65, 633-648, 1990.

Kawaguchi, K., H. Momma, and R. Iwase, VENUS project-Submarine cable recovery system, in Proceedings of the 1998 International Symposium on Undersea Technology, pp. 488-452, IEEE Ocean Engineering Society, Tokyo, Japan, 1998.

KDD, Special Issue on the Trans Pacific Cable-1, KDD Technical Jour, 42, pp. 1-141, 1964

KDD, Special Issue on the Trans Pacific Cable-2, KDD Technical Jour., 88, pp. 3-75, 1976.

Kinoshita, H., Cable-connected submarine environment monitor system, in Proceedings of International Workshop on Scientific Use of Submarine Cables, pp. 119-125, Okinawa, 1997.

Kong, L., N. Seama, H. Fujimoto, J. Kasahara, and K92-1 shipboard scientific party, Segmentation of the Mariana Trough back-arc spreading center at $18^{\circ} \mathrm{N}$, InterRidge News, 1, 2-5, 1992.

Kuramoto, S., K. Suyehiro, A. Klaus, H. Tokuyama, M. Shinohara, J. Ashi, F. Yamamoto, A. Tairai, and Shipboard scientific party, Structure of northern Izu-Bonin arc-trench system investigated by multichannel and single channel seismic reflection profiling, EOS Trans. AGU, 72(44), 247, 1991.

Matsumoto, T., M. Kimura, and C. Uechi, Surface deformation and origin of large-scale Tsunami in the southwesternmost part of the Ryukyu arc, in Proceedings of International Workshop on Scientific Use of Submarine Cables, pp. 76-77, Okinawa, 1997.

McPhaden, M. J., The tropical atmosphere ocean array is completed, Bull. Am. Meteorol. Soc., 76, 739-741, 1995.

Milburm, H. B., P. D. McLain, and C. Meining, ATLAS buoy reengineering for next decade, in Proceedings of Ocean '96, pp. 698-702, MTS/IEEE, Florida, U.S.A., 1996.
Miyazaki, N. and F. Nakahara, Establishment of receiving system of whale sound using submarine cables, in Proceedings of International Workshop on Scientific Use of Submarine Cables, pp. 78-81, Okinawa, 1997.

Miyazaki, T., Y. Murakami, and T. Nakatukasa, Development of geomagnetic and electrical fields observation system, in Proceedings of International Workshop on Scientific Use of Submarine Cables, pp. 157-159, Okinawa, 1997.

Momma, H., Y. Shirasaki, and J. Kasahara, The VENUS project-Instrumentation and underwater work system, in Proceedings of International Workshop on Scientific Use of Submarine Cables, pp. 103-108, Okinawa, Japan, 1997.

Nagaya, Y. and T. Yabuki, Detection of crustal deformation on the seafloor by acoustic ranging, in Proceedings of International Workshop on Scientific Use of Submarine Cables, pp. 189-191, Okinawa, 1997.

Nagumo, S. and D. A. Walker, Ocean bottom geoscience observation: Reuse of transoceanic telecommunication cables, EOS Trans. AGU, 70, 673 $677,1989$.

Ossaka, J., Submarine Volcano near Japan, 279 pp., Univ. Tokai Press, Tokyo, 1991 (in Japanese).

Shimura, S. (ed.), International Submarine Cable Systems, 507 pp., KDD Engineering and Consulting, Inc., Tokyo, 1984.

Shirasaki, Y., J. Kojima, and Y. Kato, The VENUS project-Data transmission distribution system, in Proceedings of International Workshop on Scientific Use of Submarine Cables, pp. 109-113, Okinawa, Japan, 1997.

Urabe, T. and M. Mizoue, Off Izu-Toho submarine system, Monthly Kaiyo, 28, 219-224, 1996 (in Japanese).

U.S. Department of Commerce, 1990 World's Submarine Cable Systems, NTIA-CR-91-42, 1991.

van der Hilst, R., S. Widiyatoro, and E. R. Engdahl, Evidence of deep mantle circulation from global tomography, Nature, 386, 578-584, 1997.

Yoshida, Y., K. Satake, and K. Abe, The large normal faulting Mariana earthquake of April 5, 1990 in uncoupled subduction zone, Geophys. Res. Lett., 19, 297-300, 1990.

Zhang, Y. S. and T. Tanimoto, High-resolution global upper mantle structure and plate tectonics, J. Geophys. Res., 98, 9793-9823, 1993.

J. Kasahara (e-mail: kasa2@eri.u-tokyo.ac.jp), T. Sato (e-mail: satot@ eri.u-tokyo.ac.jp), H. Momma (e-mail: mommah@jamstec.go.jp), and Y. Shirasaki (e-mail: sirasaki@k-marine.co.jp) 